\title{
Effects of various cryoprotective agents on the survival of unfrozen and frozen mouse embryos
}

\author{
M. Kasai, K. Niwa and A. Iritani \\ Department of Animal Science, College of Agriculture, Kyoto University, Kyoto 606, Japan
}

\begin{abstract}
Summary. The effects of DMSO, ethylene glycol, glycerol, erythritol, dimethylformamide and sucrose on the survival of unfrozen and frozen mouse morulae were examined. All the agents had a deleterious effect on survival of the unfrozen morulae at $20^{\circ} \mathrm{C}$. The harmful effect of erythritol was lower at $0^{\circ} \mathrm{C}$ and sucrose had a protective effect at that temperature. Dimethylformamide and DMSO were more harmful than ethylene glycol and glycerol at both temperatures. Higher proportions of the morulae frozen in DMSO developed into expanded blastocysts when slowly frozen samples were thawed slowly $(82 \%)$ than when they were thawed rapidly $(66 \%)$ and when rapidly frozen samples were thawed rapidly $(85 \%)$ than when they were thawed slowly $(4 \%)$. When the samples were frozen in the presence of ethylene glycol or glycerol, higher survival rates were obtained after slow (80-94\%) than rapid (1-59\%) freezing. When erythritol was used, only embryos thawed rapidly developed (31-50\%) in subsequent cultures. Sucrose and dimethylformamide did not afford cryoprotection. Morulae frozen-thawed rapidly in the presence of ethylene glycol, glycerol or erythritol and transferred to recipients developed into normal young.
\end{abstract}

\section{Introduction}

Since the first report on the successful deep-freezing of mouse embryos (Whittingham, Leibo \& Mazur, 1972), dimethylsulphoxide (DMSO) has been widely used as a cryoprotective agent. However, it was reported that glycerol is also effective for the freezing of goat (Bilton \& Moore, 1976) and cow (Bilton \& Moore, 1977) embryos. Miyamoto \& Ishibashi $(1977,1978)$ reported that mouse and rat embryos can survive after freeze-thawing in the presence of ethylene glycol and other glycols. In addition, $N, N$-dimethylformamide (Ogawa, Inoue \& Tomoda, 1977) and erythritol (Utsumi, Fujii, Nishimura \& Yuhara, 1979) have been reported to be effective for the freezing of mouse and rabbit embryos, respectively. However, little comparative work has been done on the effectiveness of these cryoprotective agents in the freezing of mammalian embryos or on the toxic or beneficial effects on embryos stored at above freezing temperatures. This study examines the effects of various cryoprotectants on the survival of unfrozen and frozen mouse embryos.

\section{Materials and Methods}

Female ICR mice (4-5 weeks old) were induced to superovulate by i.p. injections of 5-6 i.u. PMSG and 5-6 i.u. hCG given $48 \mathrm{~h}$ apart and then were paired with males of the same strain. The morulae were flushed from the excised uteri with modified phosphate-buffered saline (PBS) (Whittingham, 1971) 77-82 h after the injection of hCG and then washed twice with fresh PBS. 
To examine the effects of various cryoprotective agents on the survival of unfrozen embryos, 5-25 morulae were pipetted into $0.2 \mathrm{ml} \mathrm{PBS}$ and PBS containing 1.5 M-DMSO, $1.5 \mathrm{M}$-ethylene glycol, $1.5 \mathrm{M}$-glycerol, $1.5 \mathrm{M}$-erythritol, $1.5 \mathrm{M}$-dimethylformamide or $0.75 \mathrm{M}$-sucrose in a glass test-tube $(10 \times 100 \mathrm{~mm})$ at $20^{\circ} \mathrm{C}$ in a water bath or at $0^{\circ} \mathrm{C}$ in an ice bath. After the test-tubes were kept for $1-72 \mathrm{~h}$ at each temperature, the agents were diluted by adding $0.2,0.2$ and $0.4 \mathrm{ml}$ PBS medium at 5-min intervals at room temperature. At $5 \mathrm{~min}$ after the last addition of PBS, the morulae were recovered and washed twice in fresh PBS. The morulae were introduced into $0.4 \mathrm{ml}$ modified Krebs-Ringer-bicarbonate solution used for in-vitro fertilization of rat eggs (Toyoda \& Chang, 1974) in a plastic culture dish. The medium had been previously covered with warm paraffin oil. Morula survival was assessed by their ability to develop into expanded blastocysts during culture for $48 \mathrm{~h}$ in a $\mathrm{CO}_{2}$ incubator $\left(5 \% \mathrm{CO}_{2}\right.$ in air at $\left.37^{\circ} \mathrm{C}\right)$. At least two experiments were done and 14-55 embryos were examined at each treatment.

To examine the effects of various cryoprotectants on the survival of frozen-thawed morulae, 10-30 embryos were pipetted into $0.2 \mathrm{ml}$ PBS containing DMSO, ethylene glycol, glycerol, erythritol, dimethylformamide or $0.75 \mathrm{M}$-sucrose in a glass test-tube pre-cooled in an ice bath. Since it has been suggested that a higher concentration of DMSO is required for the rapid cooling procedure (Kasai, Niwa \& Iritani, 1980), the concentration of the cryoprotectants, except for sucrose, was $2.0 \mathrm{M}$ for rapid freezing and $1.5 \mathrm{M}$ for slow freezing. After 5-15 min, the samples were transferred to ethanol baths at -4 or $-7^{\circ} \mathrm{C}$, according to the concentrations of the cryoprotectants. A few minutes later, the samples were seeded by touching a piece of solid $\mathrm{CO}_{2}$ to the outside of the test-tube just above the level of the freezing medium. After being kept for a further $5 \mathrm{~min}$ at the seeding temperature, the samples for rapid freezing were kept in a $-20^{\circ} \mathrm{C}$ ethanol bath for $10 \mathrm{~min}$, suspended directly in liquid nitrogen vapour at $-100^{\circ} \mathrm{C}$ for $10 \mathrm{~min}$ and then plunged into liquid nitrogen at $-196^{\circ} \mathrm{C}$ (Kasai et al., 1980). The average cooling rate between -20 and $-75^{\circ} \mathrm{C}$ was $\sim 17^{\circ} \mathrm{C} / \mathrm{min}$. The samples for slow freezing were cooled to $-50^{\circ} \mathrm{C}$ at $0.33^{\circ} \mathrm{C} / \mathrm{min}$ and to $-75^{\circ} \mathrm{C}$ at $1^{\circ} \mathrm{C} / \mathrm{min}$ by adding solid $\mathrm{CO}_{2}$ to the ethanol, and then they were plunged into liquid nitrogen. After storage at $-196^{\circ} \mathrm{C}$ for $1-90$ days, the samples were thawed slowly in air at room temperature or thawed rapidly by gentle shaking in a $30-35^{\circ} \mathrm{C}$ water bath. The respective thawing rates were $\sim 25^{\circ} \mathrm{C} / \mathrm{min}$ and $\sim 360^{\circ} \mathrm{C} / \mathrm{min}$ between -75 and $-10^{\circ} \mathrm{C}$. As soon as the medium was thawed, the contents of each tube were emptied into a watch glass. The embryos frozen and thawed in the presence of DMSO, ethylene glycol, glycerol, erythritol and dimethylformamide were pipetted into PBS containing the corresponding cryoprotectant $(1.5$ or $2.0 \mathrm{M})+0.5 \mathrm{M}$-sucrose and were kept there for about $2 \mathrm{~min}$ at room temperature before transfer into PBS with $0.5 \mathrm{M}$-sucrose; with this procedure a high proportion of mouse morulae survive (Kasai et al., 1980). A few minutes later, the morulae were washed twice in fresh PBS. The embryos frozen and thawed in the presence of sucrose were transferred directly into fresh PBS and were washed. The embryos were then cultured for $48 \mathrm{~h}$ to assess their ability to develop into expanded blastocysts. Experiments were replicated 3-5 times and 80 embryos were frozen at each treatment.

To examine the further development of the embryos frozen and thawed rapidly in the presence of ethylene glycol, glycerol and erythritol, 5-6 embryos which had developed normally into blastocysts after being cultured for 20-24 h were transferred into each uterine horn of 2-4 recipients on Day 4 of pseudopregnancy, induced by mating with a vasectomized male. The recipients were mice of the IVCS strain which is characterized by 4-day cycles. The recipients were allowed to litter.

\section{Unfrozen morulae}

\section{Results}

As shown in Text-fig. 1 , the morulae stored at 0 and $20^{\circ} \mathrm{C}$ in the presence of dimethylformamide and DMSO completely lost their ability to develop into expanded blastocysts 
within 6 and $24 \mathrm{~h}$ of storage respectively. In ethylene glycol and glycerol survival rate decreased more slowly than in DMSO. The embryos stored in solutions containing erythritol and sucrose survived for longer periods when they were stored at $0^{\circ} \mathrm{C}$ than at $20^{\circ} \mathrm{C}$; in particular, remarkably high levels of embryonic viability were maintained when they were stored in sucrose at $0^{\circ} \mathrm{C}$. In contrast, the percentage survival of embryos during storage for $24 \mathrm{~h}$ in PBS or in the presence of ethylene glycol and glycerol was less when they were stored at $0^{\circ} \mathrm{C}$ than at $20^{\circ} \mathrm{C}$.

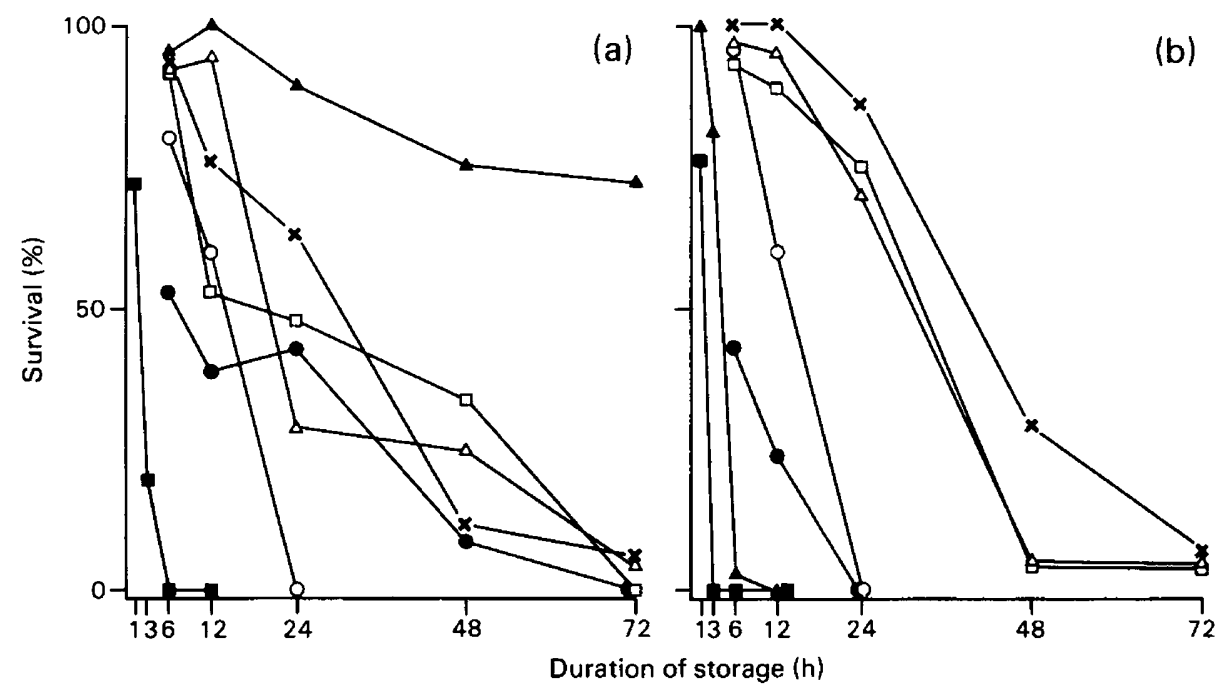

Text-fig. 1. Survival of mouse morulae assessed by their ability to develop to expanded blastocysts in culture after storage for various periods at (a) $0^{\circ} \mathrm{C}$ and (b) $20^{\circ} \mathrm{C}$ in PBS (x) and PBS containing 1.5 M-DMSO (O), 1.5 M-ethylene glycol $(\triangle), 1.5 \mathrm{M}$-glycerol ( $\square$ ), 1.5 M-erythritol $(\odot), 1.5 \mathrm{M}$-dimethylformamide $(\boldsymbol{D})$ and $0.75 \mathrm{M}$-sucrose $(\Delta)$.

\section{Frozen-thawed morulae}

The results summarized in Table 1 demonstrate that the sensitivity of embryos to the rates of freezing and thawing was largely affected by the cryoprotectant. In the samples frozen and thawed in the presence of DMSO, significantly higher proportions of embryos developed into expanded blastocysts when slowly frozen samples were thawed slowly (slow-slow procedure) than when they were thawed rapidly, and when rapidly frozen samples were thawed rapidly (rapid-rapid procedure) than when they were thawed slowly $(P<0.05)$. When samples were frozen in a solution containing ethylene glycol or glycerol, higher survival rates were obtained after slow freezing (80-94\%) than rapid freezing (1-49\%), regardless of the thawing rate. When erythritol was used as a cryoprotectant, very high proportions (96-97\%) of the morphologically normal embryos were obtained only when they were thawed rapidly, regardless of the freezing rate. However, a higher proportion of the embryos developed in subsequent cultures when they were frozen rapidly $(50 \%)$ than when they were frozen slowly $(P<0.05)$. When the embryos were frozen with sucrose, a higher percentage of morphologically normal embryos was obtained in the sample frozen-thawed by the rapid-rapid procedure than by other procedures $(P<0.01)$. However, all of the embryos frozen and thawed in sucrose were killed during the process of removing the sucrose. When dimethylformamide was used as a cryoprotectant, higher proportions of morphologically normal embryos were recovered just after thawing in the samples frozen slowly than in those frozen rapidly $(P<0.001)$ regardless of the thawing rate, but they did not develop in culture. 
Table 1. Effects of various cryoprotectants and thawing rates on survival of mouse morulae frozen and thawed rapidly or slowly

\begin{tabular}{|c|c|c|c|c|c|c|}
\hline \multirow[b]{2}{*}{$\begin{array}{l}\text { Freezing } \\
\text { rates }\end{array}$} & \multirow[b]{2}{*}{$\begin{array}{c}\text { Thawing rates } \\
\left({ }^{\circ} \mathrm{C} / \mathrm{min}\right)\end{array}$} & \multirow[b]{2}{*}{$\begin{array}{c}\text { Cryo- } \\
\text { protectant }\end{array}$} & \multirow[b]{2}{*}{$\begin{array}{l}\text { No. of embryos } \\
\text { recovered }\end{array}$} & \multicolumn{2}{|c|}{$\begin{array}{l}\text { No. of embryos } \\
\text { morphologically normal }\end{array}$} & \multirow{2}{*}{$\begin{array}{l}\text { No. of embryos } \\
\text { developed to } \\
\text { expanded } \\
\text { blastocyst } \\
\text { after } 48 \mathrm{~h} \mathrm{in} \\
\text { culture }(\%) \ddagger\end{array}$} \\
\hline & & & & $\begin{array}{c}\text { Just after } \\
\text { thawing }\end{array}$ & $\begin{array}{l}\text { After removal } \\
\text { of cryoprotectant } \\
(\%) \ddagger\end{array}$ & \\
\hline \multirow[t]{2}{*}{ Slow§ } & 25 & $\begin{array}{c}\text { DMSO } \\
\text { Ethylene glycol } \\
\text { Glycerol } \\
\text { Erythritol } \\
\text { DMFA } \\
\text { Sucrose }\end{array}$ & $\begin{array}{l}76 \\
79 \\
76 \\
73 \\
76 \\
77\end{array}$ & $\begin{array}{c}73(96)^{c} \\
77(97)^{c} \\
71(93)^{c} \\
0(0) \\
48(63)^{c} \\
29(38)\end{array}$ & $\begin{array}{c}68(89) \\
76(96) \\
69(91) \\
0(0) \\
46(61) \\
0(0)\end{array}$ & $\begin{array}{l}62(82)^{\mathrm{a}} \\
74(94)^{\mathrm{a}} \\
61(80)^{\mathrm{c}} \\
0(0) \\
0(0) \\
0(0)\end{array}$ \\
\hline & 360 & $\begin{array}{c}\text { DMSO } \\
\text { Ethylene glycol } \\
\text { Glycerol } \\
\text { Erythritol } \\
\text { DMFA } \\
\text { Sucrose }\end{array}$ & $\begin{array}{l}77 \\
72 \\
77 \\
78 \\
75 \\
76\end{array}$ & $\begin{array}{l}72(94)^{\mathrm{c}} \\
67(93)^{\mathrm{c}} \\
75(97)^{\mathrm{c}} \\
75(96)^{\mathrm{c}} \\
36(48)^{\mathrm{c}} \\
49(64)\end{array}$ & $\begin{array}{l}64(83) \\
64(89) \\
75(97) \\
44(56) \\
17(23) \\
0(0)\end{array}$ & $\begin{array}{l}51(66) \\
60(83) \\
68(88)^{\mathrm{c}} \\
24(31) \\
0(0) \\
0(0)\end{array}$ \\
\hline \multirow[t]{2}{*}{ Rapid§ } & 25 & $\begin{array}{c}\text { DMSO } \\
\text { Ethylene glycol } \\
\text { Glycerol } \\
\text { Erythritol } \\
\text { DMFA } \\
\text { Sucrose }\end{array}$ & $\begin{array}{l}75 \\
74 \\
77 \\
71 \\
73 \\
72\end{array}$ & $\begin{array}{c}38(51) \\
12(16) \\
26(34) \\
0(0) \\
1(1) \\
26(36)\end{array}$ & $\begin{array}{c}8(11) \\
3(4) \\
18(23) \\
0(0) \\
0(0) \\
0(0)\end{array}$ & $\begin{array}{c}3(4) \\
1(1) \\
26(34) \\
0(0) \\
0(0) \\
0(0)\end{array}$ \\
\hline & 360 & $\begin{array}{c}\text { DMSO } \\
\text { Ethylene glycol } \\
\text { Glycerol } \\
\text { Erythritol } \\
\text { DMFA } \\
\text { Sucrose }\end{array}$ & $\begin{array}{l}71 \\
70 \\
72 \\
66 \\
73 \\
75\end{array}$ & $\begin{array}{c}64(90)^{c} \\
30(43) \\
51(71) \\
64(97)^{c} \\
9(12) \\
65(87)^{b}\end{array}$ & $\begin{array}{l}59(83) \\
13(19) \\
37(51) \\
51(77) \\
8(11) \\
0(0)\end{array}$ & $\begin{array}{c}60(85)^{\mathrm{a}} \\
14(20) \\
35(49) \\
33(50)^{\mathrm{a}} \\
0(0) \\
0(0)\end{array}$ \\
\hline
\end{tabular}

Statistical comparisons $\left(\chi^{2}\right.$ test) were made among slow-slow, slow-rapid, rapid-slow and rapid-rapid procedures of freeze-thawing in each cryoprotectant: values indicated by superscripts are significantly higher: ${ }^{a} P<0.05 ;{ }^{\mathrm{b}} P<0.01 ;^{\mathrm{c}} P<0.001$.

$* 1.5 \mathrm{M}$ for slow freezing and $2.0 \mathrm{M}$ for rapid freezing except for sucrose which was $0.75 \mathrm{M}$ for both.

† Embryos were examined 1-2 $\mathrm{h}$ after start of culture.

$\ddagger$ Percentage of the number of embryos recovered.

$\S$ For details of freezing rates, see text.

Of 47, 24 and 20 embryos frozen-thawed rapidly in the presence of ethylene glycol, glycerol and erythritol, and transferred into recipients, 4 (9\%), $5(21 \%)$ and $7(35 \%)$ normal young were obtained, respectively.

\section{Discussion}

From the results of this study, it is quite clear that the 6 cryoprotective agents examined have different effects on the survival of unfrozen and frozen mouse morulae.

Few attempts have been made to preserve mammalian embryos in the presence of various cryoprotectants at above freezing temperatures for a prolonged period. Whittingham (1974) found no decrease in viability of mouse 8-cell embryos, morulae or early blastocysts during storage in PBS at $0^{\circ} \mathrm{C}$ for up to $48 \mathrm{~h}$. In the present study, however, the survival of mouse morulae decreased greatly when stored in PBS at 0 and $20^{\circ} \mathrm{C}$ for $48 \mathrm{~h}$. This discrepancy cannot be explained at present. Hafez (1963) reported that the addition of $7 \%$ glycerol to the storage medium had a harmful effect on rabbit embryos stored at $10^{\circ} \mathrm{C}$, and the 6 cryoprotectants tested here were also rather harmful for the survival of mouse morulae at $20^{\circ} \mathrm{C}$, although 
ethylene glycol and glycerol were less harmful than dimethylformamide, DMSO, erythritol and sucrose. However, the toxicity of erythritol and sucrose at $20^{\circ} \mathrm{C}$ was largely decreased when the embryos were stored at $0^{\circ} \mathrm{C}$, possibly due to the low permeabilities of these agents at this temperature. It is presumed that agents with higher molecular weights are less able to permeate into the cells and that the permeability of an agent is higher at 20 than $0^{\circ} \mathrm{C}$ (Leibo, 1977). The reason for the increased survival rate of the embryos stored at $0^{\circ} \mathrm{C}$ in the presence of sucrose over that of control embryos is not clear: a shrunken state may be beneficial for embryonic survival because embryos in sucrose remained shrunk for up to $72 \mathrm{~h}$ of storage at $0^{\circ} \mathrm{C}$. Nevertheless, the protective effect of sucrose at $0^{\circ} \mathrm{C}$ may lead to a method whereby mammalian embryos can be preserved for several days.

The results of the present experiments on freezing of mouse morulae showed that dimethylformamide and sucrose did not afford cryoprotection but various proportions of frozen-thawed embryos survived when DMSO, ethylene glycol, glycerol or erythritol was used. It was originally reported that slow rates of cooling $\left(0.2-0.8^{\circ} \mathrm{C} / \mathrm{min}\right)$ and thawing $\left(4-25^{\circ} \mathrm{C} / \mathrm{min}\right)$ were essential for maximal survival of mouse embryos frozen to $-196^{\circ} \mathrm{C}$ in the presence of DMSO (Whittingham et al., 1972; Leibo, Mazur \& Jackowski, 1974). The present experiments confirmed this finding when embryos were frozen slowly in the presence of DMSO and ethylene glycol. When embryos were frozen with glycerol, however, the survival was not affected by thawing rates. Moreover, when erythritol was used, embryos survived only after rapid thawing. These results indicate that slow thawing is not always essential for the survival of slowly cooled embryos, but may even be harmful in some cases. Cryoprotectants with higher molecular weights may necessitate rapid thawing of embryos after slow cooling.

Mouse embryos can survive rapid cooling in the presence of DMSO if they are thawed rapidly (Whittingham, Wood, Farrant, Lee \& Halsey, 1979; Kasai et al., 1980; Wood \& Farrant, 1980). The present results also show that mouse embryos can survive when frozen and thawed rapidly if other cryoprotectants are used. Although the highest survival rate was obtained with DMSO (85\%) in our rapid method, it might be possible to increase the survival rate after rapid freeze-thawing in ethylene glycol, glycerol and erythritol. If so, ethylene glycol and glycerol would be especially useful cryoprotectants because they are less toxic than DMSO (Text-fig. 1).

No embryos developed after freeze-thawing in dimethylformamide, probably because of its high toxicity (Text-fig. 1). When mouse morulae are frozen-thawed rapidly in the presence of acetamide, $N, N$-dimethylacetamide or lactamide, morphologically normal embryos are recovered (4-45\%), but subsequent development in vitro is quite limited (0.5\%) (unpublished data). The amide group therefore seems to be too toxic to mouse embryos to be used as cryoprotectants.

When morulae were frozen in sucrose, morphologically normal embryos were recovered just after thawing, indicating that prior penetration of a cryoprotectant is not essential for the survival of frozen embryos. When these embryos were resuspended in an isotonic PBS, however, all of the normal morulae were swollen and broken, presumably by excess water entry. This fact strongly suggests that sucrose penetrates the embryos during freezing and/or thawing. Labelled sucrose has been found inside red blood cells after freeze-thawing (Daw, Farrant \& Morris, 1973). Sucrose has been shown to afford protection to some kinds of cells during freeze-thawing (Luyet, 1965) but not to mammalian embryos (Whittingham, 1971; Wilmut, 1972; Wilmut \& Rowson, 1973). Sucrose may not be a cryoprotectant for practical use in embryo freezing, but it could be used for study of the survival mechanism during freeze-thawing.

It has been reported that mouse embryos frozen and thawed rapidly in the presence of DMSO can develop into normal live young after transfer (Kasai et al., 1980). The present study demonstrates that normal young can be also obtained from embryos frozen-thawed rapidly in the presence of ethylene glycol, glycerol and erythritol.

This work was supported by a grant from the Ministry of Agriculture, Forestry and Fishery of Japan. 


\section{References}

Bilton, R.J. \& Moore, N.W. (1976) In vitro culture, storage and transfer of goat embryos. Aust. J. biol. Sci. 29, 125-129.

Bilton, R.J. \& Moore, N.W. (1977) Successful transport of frozen cattle embryos from New Zealand to Australia. J. Reprod. Fert. 50, 363-364.

Daw, A., Farrant, J. \& Morris, G.J. (1973) Membrane leakage of solute after thermal shock or freezing. Cryobiology 10, 126-133.

Hafez, E.S.E. (1963) Storage of fertilized ova. Int. J. Fert. 8, 459-466.

Kasai, M., Niwa, K. \& Iritani, A. (1980) Survival of mouse embryos frozen and thawed rapidly. $J$. Reprod. Fert. 59, 51-56.

Leibo, S.P. (1977) Fundamental cryobiology of mouse ova and embryos. In The Freezing of Mammalian Embryos (Ciba Fndn Symp. No. 52 (new series)), pp. 69-92. Eds K. Elliott \& J. Whelan. Elsevier/North Holland, Amsterdam.

Leibo, S.P., Mazur, P. \& Jackowski, S.C. (1974) Factors affecting survival of mouse embryos during freezing and thawing. Expl Cell Res. 89, 79-88.

Luyet, B.J. (1965) Attempt at correlating some of the extant data on low-temperature preservation of various cells. Fedn Proc. Fedn Am. Socs exp. Biol. 24, S 315-322.

Miyamoto, H. \& Ishibashi, T. (1977) Survival of frozen-thawed mouse and rat embryos in the presence of ethylene glycol. J. Reprod. Fert. 50, $373-375$.

Miyamoto, H. \& Ishibashi, T. (1978) The protective action of glycols against freezing damage of mouse and rat embryos. J. Reprod. Fert. 54, 427-432.

Ogawa, S., Inoue, K. \& Tomoda, H. (1977) Survival of mouse embryos frozen in the presence of $N, N$ - dimethylformamide. Jpn J. Zootech. Sci. 48, Suppl., 25, Abstr.

Toyoda, Y. \& Chang, M.C. (1974) Fertilization of rat eggs in vitro by epididymal spermatozoa and the development of eggs following transfer. $J$. Reprod. Fert. 36, 9-22.

Utsumi, K., Fujii, Y., Nishimura, K. \& Yuhara, T. (1979) Simple freezing method of rabbit embryos by liquid nitrogen gas. Jpn J. Anim. Reprod. 25, Suppl., 53-54.

Whittingham, D.G. (1971) Survival of mouse embryos after freezing and thawing. Nature, Lond. 233, 125-126.

Whittingham, D.G. (1974) Embryo banks in the future of developmental genetics. Genetics, Princeton 78, 395-402.

Whittingham, D.G., Leibo, S.P. \& Mazur, P. (1972) Survival of mouse embryos frozen to $-196^{\circ} \mathrm{C}$ and $-269^{\circ} \mathrm{C}$. Science, N.Y. 178, 411-414.

Whittingham, D.G., Wood, M., Farrant, J., Lee, H. \& Halsey, J.A. (1979) Survival of frozen mouse embryos after rapid thawing from $-196^{\circ} \mathrm{C}$. J. Reprod. Fert. 56, 11-21.

Wilmut, I. (1972) The effect of cooling rate, warming rate, cryoprotective agent and stage of development on survival of mouse embryos during freezing and thawing. Life Sciences 11, 1071-1079.

Wilmut, I. \& Rowson, L.E.A. (1973) Experiments on the low-temperature preservation of cow embryos. Vet. Rec. 92, 686-690.

Wood, M.J. \& Farrant, J. (1980) Preservation of mouse embryos by two-step freezing. Cryobiology 17, 178-180.

Received 2 December 1980 